\title{
Influence of Ultra Injection Pressure with Dynamic Injection Timing on CRDI Engine Performance Using Simarouba Biodiesel Blends
}

\author{
Srinath Pai ${ }^{*}$, Abdul Sharief ${ }^{2}$ and Shiva Kumar ${ }^{3}$ \\ ${ }^{1}$ Department of Mechanical Engineering, Srinivas School of Engineering, Mangalore, \\ affiliated to Visvesvaraya Technological University Belagaum - 575014, India \\ *Email: srinath_pai@rediffmail.com \\ Phone: +918242477456 \\ ${ }^{2}$ Department of Mechanical Engineering, P. A. College of Engineering \&Technology, \\ Mangalore, affiliated to Visvesvaraya Technological \\ University Belagaum- 574153, India, \\ ${ }^{3}$ Department of Mechanical Engineering, Manipal Institute of Technology, \\ Manipal Academy of Higher Education, Manipal - 576104, India
}

\begin{abstract}
This paper presents an experimental investigation carried out on a "single cylinder diesel engine upgraded with a common rail direct injection (CRDI) system. Tests were conducted by fuelling high-speed diesel (HSD) and Simarouba biodiesel (SOME) blends to study the influence of injection pressure (IPR) and injection timing (ITG) on the performance and emissions. Four unique IPR of 400 bar, 600 bar, 800 bar and 1000 bar with four different ITG of $10^{\circ}, 13^{\circ}, 15^{\circ}$ and $18^{\circ}$ before top dead center (bTDC) combinations were taken for study with the engine loading varied from $25 \%$ to full load. Critical performance parameter like brake thermal efficiency (BTE) and brake specific fuel consumption (BSFC) were calculated, while, the primary emission parameters of the diesel engine, the NOx and smoke opacity were recorded. From the results it is concluded that the given engine recorded favourable results at IPR- ITG combination of 800 bar and $13^{\circ} \mathrm{bTDC}$ for all fuels tested at higher load conditions specifically at $75 \%$ load to full load. Among the different fuels investigated SOME30 yielded the best performance and moderate emission at this combination of IPR- ITG.
\end{abstract}

Keywords: Biodiesel; performance; emission; common rail direct injection (CRDI), engine; injection pressure and timing.

\section{INTRODUCTION}

Alternative fuels are seriously examined for replacement of the diesel fuel. Use of biodiesel produced using renewable sources, which is an eco-friendly and safe fuel with low emission values with ecological benefits in CI engines, is regarded as an alternative way to decrease the pollutant level and the potential or probable carcinogenic level [1]. Biodiesel is gaining importance as an alternative to conventional fuels because of their useful properties and compatibility with the petroleum-based diesel fuel. They also offer promise on the long-term fuel-source sustainability and minimum environmental illeffects after combustion [2]. Biodiesel- fuelled engines give a large opportunity to cope with the fundamental problems facing society, specifically increased energy utilization and global warming. The use of biodiesel with technologically advanced injection strategy has shown a significant impact on diesel engine emissions [3]. Biodiesel is non- 
flammable, non-explosive in contrast to diesel fuel [4]. Direct injection diesel engine (DIDE) can be operated with up to $20 \%$ of biodiesel blending with diesel without any requirement of enormous alterations in any diesel engine [5].

Research work carried out on diesel engines fueled with biodiesel, with no change in the existing engine test rig, has shown that the engine can produce equal power output, BTE and slightly increase in emissions as compared to diesel. However, the study indicated that the blending of biodiesel with the diesel could be done only up to $20 \%$. It is also advised that the increased percentage of mixing is conceivable in a high-pressure fuel injection system (HPFIS) [5]. The increased fuel injection pressure (FIP) causes the reduction in the size of the injected fuel droplets resulting in better atomization, and faster evaporation of the fuel particles. This is will result in a more complete combustion of the fuel leading to improved thermal efficiency and increased power output. Also, the combustion delay time is reduced with increased IPR. Due to this, the mixture is formed in a shorter time, the amount of the nitric oxide (NOx) formed reduced considerably due to the ignition time delay [6-8]. Increasing IPR will remove the accumulation of particles, which results in a significant decrease in particle total mass concentration and reduces soot formation [9]. Advanced ITG produces lower smoke compared with retarded ITG [10]. The NOx emission is minimized by retarding the ITG [11-13]. With retarded ITG the cylinder pressure and heat release rates are improved [14]. The combined effect of ITG advance and increased IPR has increased brake thermal efficiency [15, 16]. Thus, it can be concluded that a proper combination of IPR and ITG will help in improved combustion resulting in improved performance and emission parameters of a diesel engine. A suitable blend of IPR and ITG will lead to enhanced spray characteristics with better atomization promoting a total fuel-air mixing, which is the basis for the enhanced combustion process [8]. A glance, on the few surveys of the investigations carried out by various researchers on diesel engine fuelled with biodiesel at different IPR and ITG, is discussed underneath:

T. Balusamy et al. studied the effect of IPR and ITG on a DIDE [15]. They observed the gain in the BTE and further noticed a reduction in $\mathrm{CO}$ (by $25 \%$ ), $\mathrm{HC}$ (from 9.5 to $7.7 \mathrm{ppm}$ ), smoke (from $48 \%$ to $35 \%$ ) for increased IPR with advanced ITG. Venkatraman et al. [17] studied Pungam biodiesel blends with diesel and observed that an increased compression ratio (CR), IPR and ITG results in improved the BTE, reduced the BSFC and emissions. Metin Gumus et al. [18] have concluded that BSFC and smoke opacity decreased with an increase in the biodiesel amount in diesel along with the increased IPR. G.R. Kannan et al. [19] in their study on a DI engine at varying IPR and IGT, have found the higher BTE for 240 bar and $25.5^{\circ}$ bTDC. Extensive research was done by Cenk Sayin et al. [20] on the DI engine to find the FIP effect using canola oil biodiesel blends. They emphasized that to achieve higher BTE and decreased BSFC, high IPR is necessary. G.R. Kannan et al. [21] have found that the collective effect of high IPR and an advanced ITG brings out in improved BTE, cylinder gas pressure (CGP), Heat Release Rate (HRR) and reduced NOx and Particulate matter from Waste Cooking oil biodiesel. Venkanna Krishnamurthy Belagur et al. [22] conducted an experimental study using Honne Oil Methyl Ester (HOME) with diesel. From their research, they reported that the increased ITG had improved combustion parameters leading to increasing BTE and reduction in emissions. S. Jaichandar et al. [23] in their study have revealed an increase in BTE (34.31\%), reduced SFC $(0.243 \mathrm{~kg} / \mathrm{kW}-\mathrm{hr}), \mathrm{CO}$, UHC and smoke intensity. The NOx emission was increased at high IPR of 220 bar. Avinash Kumar Agarwal et al. [24] in their investigative work on a CRDI engine used Karanja biodiesel blends, have observed improved BTE with reduced the emissions. Deepesh Sonar et al. 
[25] used diesel-Mahua oil blends in their study on an engine operated at different IPR. Their study revealed an improvement in BTE and BSFC at IPR of 226 bar and also the drastic reduction in CO, UHC emission and a marginal increase in The NOx emissions. Atul Dhar et al. [26] used Karanja biodiesel blends for their study and observed an increase in BSFC and BTE for Karanja biodiesel blends than diesel. Srinath Pai et al. [5] have in their investigation of the higher Fuel IPR effect on biodiesel blends, have concluded that the high IPR increases the atomization, evaporation, and penetration of the denser biodiesel blend. R. Senthil et al. [27] have observed the increase in the NOx emission and decrease in $\mathrm{CO}$ and $\mathrm{HC}$ at advanced ITG.

The author would like to bring to the notice of the readers that, a previous experimental investigation carried out revealed the combination of IPR of 800 bar and IT of $18^{\circ} \mathrm{bTDC}$ has proved to be the best combination for improved performance of the CRDI engine [8]. In which the investigation was carried out for a combination of IPR of 600,800 and 1000 bar with ITG of $10^{\circ}, 18^{\circ}, 23^{\circ}$ and $28^{\circ}$ bTDC combinations [8]. Further, owing to curiosity, a continuation of the investigation was carried at advance injection timing of $10^{\circ}, 13^{\circ}$, and $15^{\circ}$ bTDC for the above combination of pressures on the same engine set up. The results of this work are presented in this paper. The discussion is mainly focused on the engine performance at higher loads specifically at $75 \%$ and $100 \%$ because this is the ideal operating load in any IC engine. CRDI engine under study has performed better in the load range from $75 \%$ to $100 \%$ with an improving trend in performance from 75 to $100 \%$. In this paper, the analysis at $75 \%$ load is only discussed and similar results are also obtained at $100 \%$ load.

\section{EXPERIMENTAL SETUP}

\section{Design of Experiment}

The study aims to find out the IPR and ITG influence on a C.I engine performance and emissions for HSD and Simarouba biodiesel (SOME) blends. A single-cylinder diesel engine upgraded with CRDI system was used for the investigation. The properties of the fuels used in this study are given in Table 1. Specifications of the 5 Gas Analyzer are mentioned in Table 2. Specifications of the smoke meter are provided in Table 3.

Table 1. HSD and SOME properties.

\begin{tabular}{|c|c|c|c|c|c|}
\hline Properties & Test method & HSD & SOME 100 & SOME20 & SOME30 \\
\hline $\begin{array}{l}\text { Relative density at } \\
15^{\circ} \mathrm{C}(\mathrm{g} / \mathrm{mL})\end{array}$ & ASTMD-1298 & 0.840 & 0.868 & 0.838 & 0.846 \\
\hline Cetane number & ASTMD-4737 & 48 & 52 & 49 & 50 \\
\hline $\begin{array}{l}\text { Calorific value } \\
\mathrm{MJ} / \mathrm{kg}\end{array}$ & ASTMD-4868 & 44.8 & 39.8 & 43.8 & 43.3 \\
\hline Flash point $\left({ }^{\circ} \mathrm{C}\right)$ & ASTMD-93 & 55 & 165 & 79 & 88 \\
\hline $\begin{array}{l}\text { Kinematic viscosity } \\
\text { at } 40^{\circ} \mathrm{C}(\mathrm{cSt})\end{array}$ & ASTMD-445 & 2.35 & 4.8 & 3.1 & 3.5 \\
\hline
\end{tabular}


Table 2. Specifications of the INDUS PEA 205, 5 gas analyser.

\begin{tabular}{llll}
\hline Type of gas & Measurement range & Data resolution & Instrument accuracy \\
\hline $\mathrm{CO}$ & 0 to $15 \%$ & $0.001 \%$ & $\pm 0.06 \%$ \\
$\mathrm{CO}_{2}$ & 0 to $20 \%$ & $0.01 \%$, & $\pm 0.05 \%$ \\
$\mathrm{O}_{2}$ & 0 to $25 \%$ & $0.01 \%$, & $\pm 0.1 \%$ \\
$\mathrm{HC}$ & 0 to $30000 \mathrm{ppm}$ & $1 \mathrm{ppm}$ & $\pm 12 \mathrm{ppm}$ \\
$\mathrm{NOx}$ & 0 to $5000 \mathrm{ppm}$ & $1 \mathrm{ppm}$ & $\leq 500 \mathrm{ppm}: \pm 50 \mathrm{ppm}$. \\
& & & $\geq 500 \mathrm{ppm}: \pm 20 \mathrm{ppm}$ \\
\hline
\end{tabular}

Table 3. Specifications of AVL 437 smoke meter.

\begin{tabular}{ll}
\hline Measuring range & 0 to $100 \mathrm{HSU}$ (Hatridge smoke units) \\
\hline Smoke Temperature & $250^{\circ} \mathrm{C}$ (Maximum at the entrance) \\
Ambient temperature & 0 to $50^{\circ} \mathrm{C}$ humidity $90 \%$ at $50{ }^{\circ} \mathrm{C}$ (Non- \\
& conditioning) \\
Power Supply & $205 \mathrm{~A}, 11.5-36 \mathrm{~V}$ DC \\
Principle & light absorption principle \\
\hline
\end{tabular}

\section{Experimental Procedure}

The experiments were conducted for four different loads of $25 \%, 50 \%, 75 \%$ and $100 \%$ loading, with constant engine speed of $1500 \mathrm{rpm}$ and compression ratio of 16.5. FIP was varied from 400 bar to 1000 bar in steps of 200 bar. For each IPR, ITG is varied in steps of $10^{\circ}, 13^{\circ}, 15^{\circ}$ and $18^{\circ}$ bTDC. Experiments were conducted for all combinations of IPRs, ITGs at each of the load combinations using HSD, SOME20 and SOME30 as fuels. The effect of IPRs and ITGs on BTE, BSFC, The NOx and Smoke opacity are analyzed.

Figure 1 and Figure 2 are the photographic views of the fuel injector and engine respectively. The engine specifications of the fuel injector and engine with details are given in Table 4 and Table 5 respectively. The existing engine had necessary the arrangements to measure the load, fuel consumption, air consumption, temperatures at salient points. High accuracy piezoelectric sensors were utilized to measure the gas, combustion and fuel injection pressure. For the crank angle record, an encoder setup was used. During the experiments, compression ratio and engine speed were kept on constant for 16.5 and $1500 \mathrm{rpm}$, respectively.

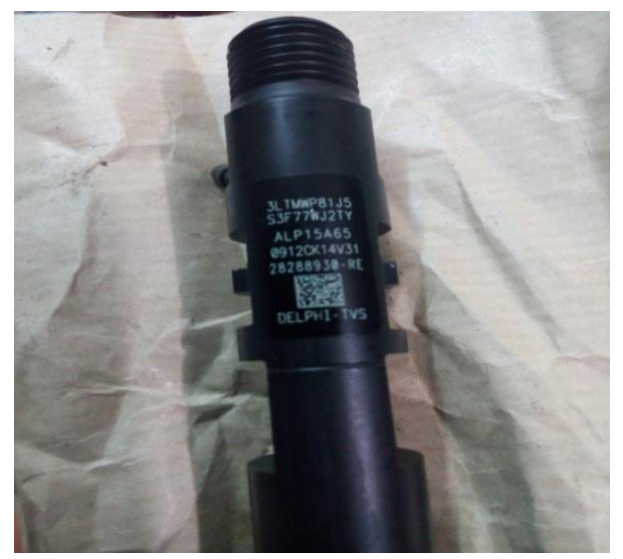

Figure 1. Fuel injector. 


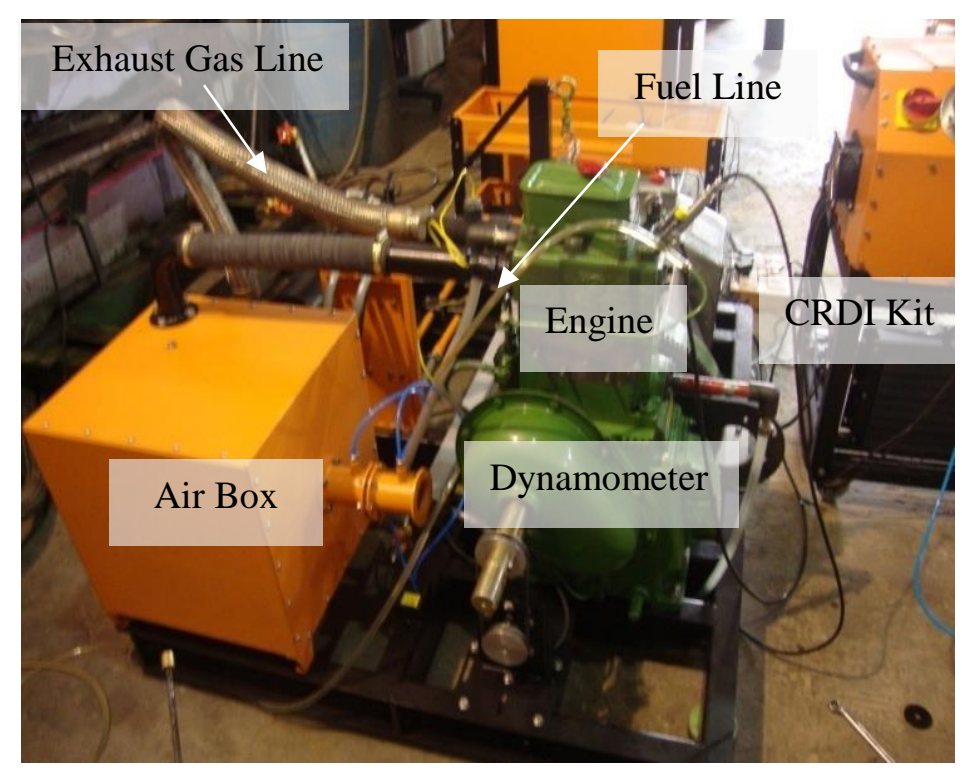

Figure 2. Photographic view of the engine setup.

Table 4. Specification of the injector.

\begin{tabular}{lll}
\hline Sl. No. & Parameter & Specifications \\
\hline 1 & Injector & Delphi - TVS \\
2 & Holes in the nozzle & 1 \\
3 & Nozzle diameter & $0.19 \mathrm{~mm}$ \\
4 & Injector operating pressure & $2000 \mathrm{bar}$ \\
5 & Injection Pressure used & $1000 \mathrm{bar}$ \\
\hline
\end{tabular}

Table 5. Engine specifications.

\begin{tabular}{lll}
\hline Sl.No. & Parameter & Specifications \\
\hline 1 & Engine Type & AV1 \\
2 & No of cylinders & Single \\
3 & Rated power & $5 \mathrm{HP}(3.7 \mathrm{~kW}) @ 1500 \mathrm{RPM}$ \\
4 & No of strokes & Four-stroke \\
5 & Nozzle opening pressure & $200 \mathrm{bar}$ \\
6 & Start of injection (SOI) timing & $23^{\circ} \mathrm{bTDC}$ \\
7 & Cylinder diameter (Bore) & 0.0875 metre \\
8 & Stroke length & $0.11 \mathrm{~m}$ \\
9 & Compression ratio & $16.5: 1$ \\
10 & Specified Fuel & H. S. Diesel \\
\hline
\end{tabular}




\section{RESULTS AND DISCUSSION}

\section{Influence of Injection Pressure and Injection Timing on Performance}

\section{Brake thermal efficiency}

Figure 3 analyses the results obtained from the influence of IPR and ITG on BTE for 75\% loading with HSD and SOME blends (SOME20 and SOME30). It is noted that BTE for SOME blends was higher than HSD at all combinations of IPR and IRG. Similar results were by Avinash Kumar Agarwal [24] in his experimental investigation. The primary cause for BTE improvement of SOME blends is the more oxygen content of biodiesel. Hence, the blended fuel helps to improve the combustion and results in better BTE [2]. The maximum BTE has observed for SOME30 at all the IPR- ITG combinations. V.K Shahir has also obtained the best BTE for B30 [28]. At 400 bar with 75\% loading, maximum BTE obtained for SOME30 is about $27.92 \%$ at $18^{\circ}$ bTDC. Similarly, for SOME30 at the same load, at 600 bar and $15^{\circ}$ bTDC, at 800 bar and $13^{\circ} \mathrm{bTDC}$ and 1000 bar and $10^{\circ}$ bTDC, the BTE values recorded were $28.87 \%, 31.29 \%$ and $29.11 \%$ respectively. The highest BTE observed for SOME30 is at IPR 800 bar with ITG $13^{\circ}$ bTDC combination. At $100 \%$ load for the same combination of IPR and ITG, maximum BTE of $35.80 \%$ is noticed for SOME30. This is due to the better atomization and better combustion at the proper combination of higher IPR [20, 21, 23] and ITG [24]. Increasing IPR decreases the injection span, prompting the finest spray droplets, which enhances the fuel-air mixing, subsequently expanding the pre-mixed heat release. Retarding ITG causes an increase in thermal efficiency [12].

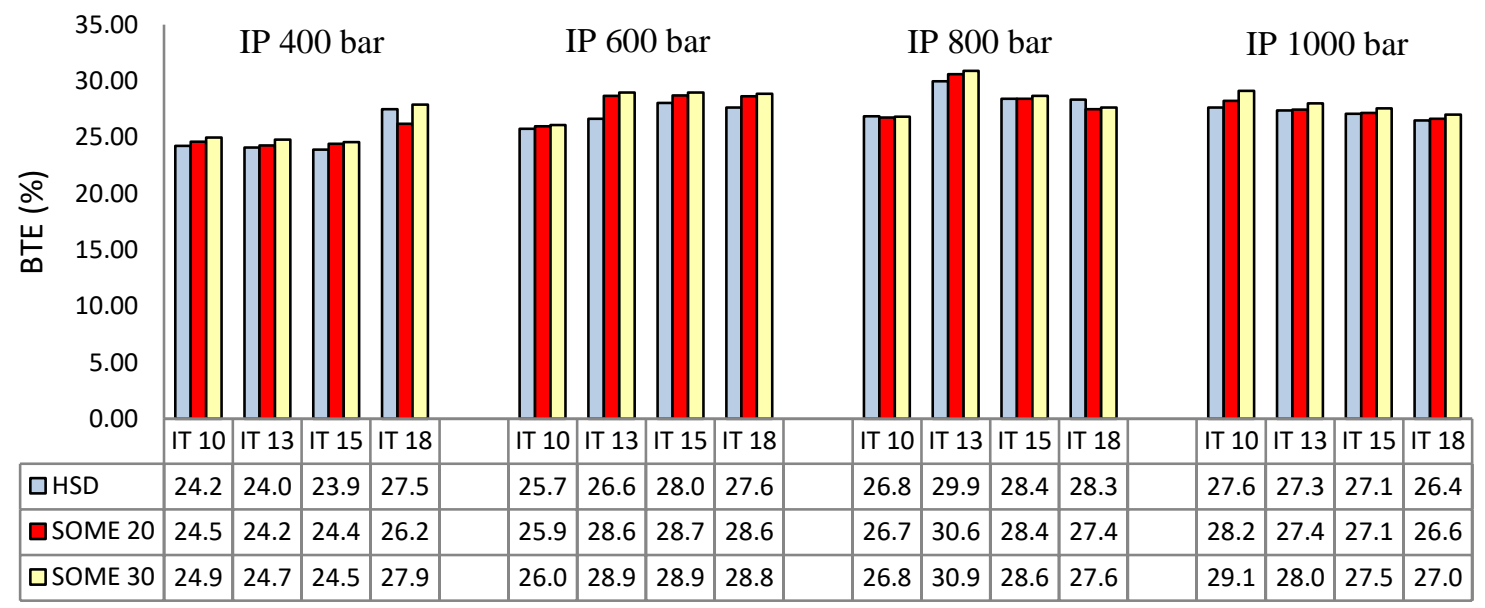

Figure 3: IPR-ITG V/S BTE.

\section{Specific fuel consumption}

The variations of the BSFC, for 75\% load for SOME20, SOME30 and HSD are shown in Figure 4. The BSFC has less value for HSD with at each of the IPR- ITG combinations. Among the all the fuels, the lowest value of BSFC found is $0.2657 \mathrm{~kg} / \mathrm{kW}-\mathrm{hr}$ at IPR of 800 bar at $13^{\circ}$ bTDC for SOME30. At the same combination at $100 \%$ load, BSFC $(0.23224 \mathrm{~kg} / \mathrm{kW}-\mathrm{hr})$ has recorded the minimum for SOME30. This may be due to higher oxygen and higher IPR, which contributes to better combustion. Similar results and 
reasons were reported by V.K Shahir [28]. Regardless of the type of fuel tested, the BSFC was increased with advancing ITG, and it was observed that the BSFC reduced with an increase in the IPR. Lower combustion is attributed to low IPR where there is oxygen starvation due to the least penetration, less dispersion of the fuel and improper air mixing [23]. A similar study by Avinash Kumar Agarwal et al. [24] had concluded that at higher IPRs, fuel energy was most effectively changed over into useful power when SOI timing was closer to TDC. The minimum BSFC has been observed for increased IPR with dynamic ITG near to TDC, hence obtained results are justifiable.

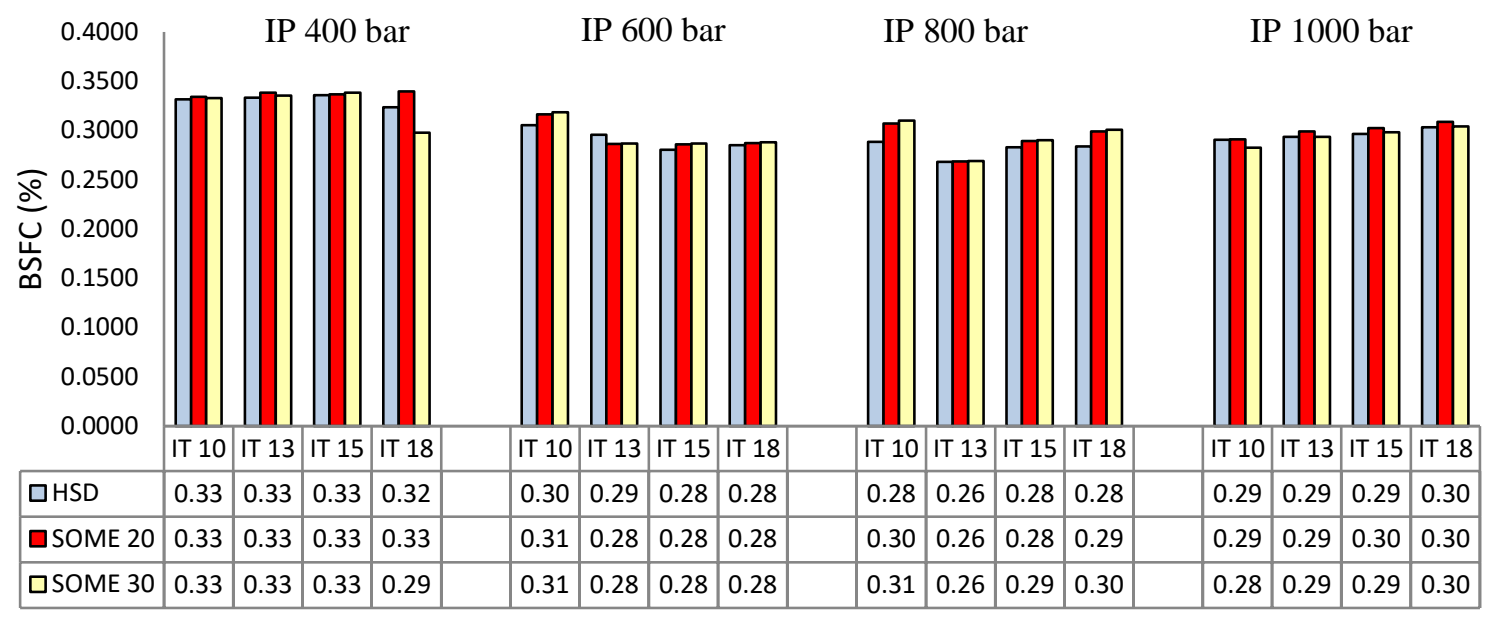

Figure 4: Influence of IP - IT on BSFC at $75 \%$ load

\section{Influence of Injection Pressure and Injection Timing on Emissions}

\section{Nitrogen oxides (NOx) emission}

Influences of IPR and ITG on the NOx for 75\% load for SOME20, SOME30 and HSD fuel are plotted in Figure 5. It is apparent that the NOx emission increased with an increment in IPRs for all the fuel utilised and decreased with retarding ITG. Similar results were obtained by Peng Ye [3] in his research. It is also observed that the NOx emission increased with an increase in SOME blending percentage, this is due to the increase in the amount of oxygen in the blend, which in turn enhances peak cylinder temperatures, and hence the NOx formation [29, 30]. Similar outcomes were obtained by the other researchers $[2,24,28,29]$. It is also believed that the formation of the NOx in the CI engines depends on the element concentration within the flammable mixture, a peak cylinder temperature of the composting mixture at [24, 31]. Generally, the NOx increases with an IPR for all test fuel. The reason for this could be the highest average gas temperature and residence time at higher IPR.

Among 75\% loading results, the NOx value is the maximum (928 ppm) for SOME30 at 1000 bar and $10^{\circ} \mathrm{bTDC}$ combination and minimum (502 ppm) for HSD at IPR 400 bar $18^{\circ}$ bTDC combination. Whereas, the minimum box of $450 \mathrm{ppm}$ is obtained for HSD at IPR-ITG combination of 800 bar- $13^{\circ}$ bTDC at $100 \%$ load. The reason is at higher IPRs; the delayed ITG caused accelerated amounts of fuel to start combustion after top dead centre (TDC), leading to lower cylinder pressure peak values and reduced cylinder temperatures. As a result, the NOx emission concentration gradually decreases. The reduced NOx emissions for SOME biodiesel are the cause of the long chain lengths, higher $(\mathrm{CN})$ and higher degrees of saturation[32]. The NOx emissions were reduced by 
retarding the ITG [24]. Ultra IPR, with dynamic ITG, will help to cut down the NOx [33]. Numerous studies have reported that the NOx emissions from biodiesel usage depend upon the kind of engine used and furthermore engine working conditions [24].

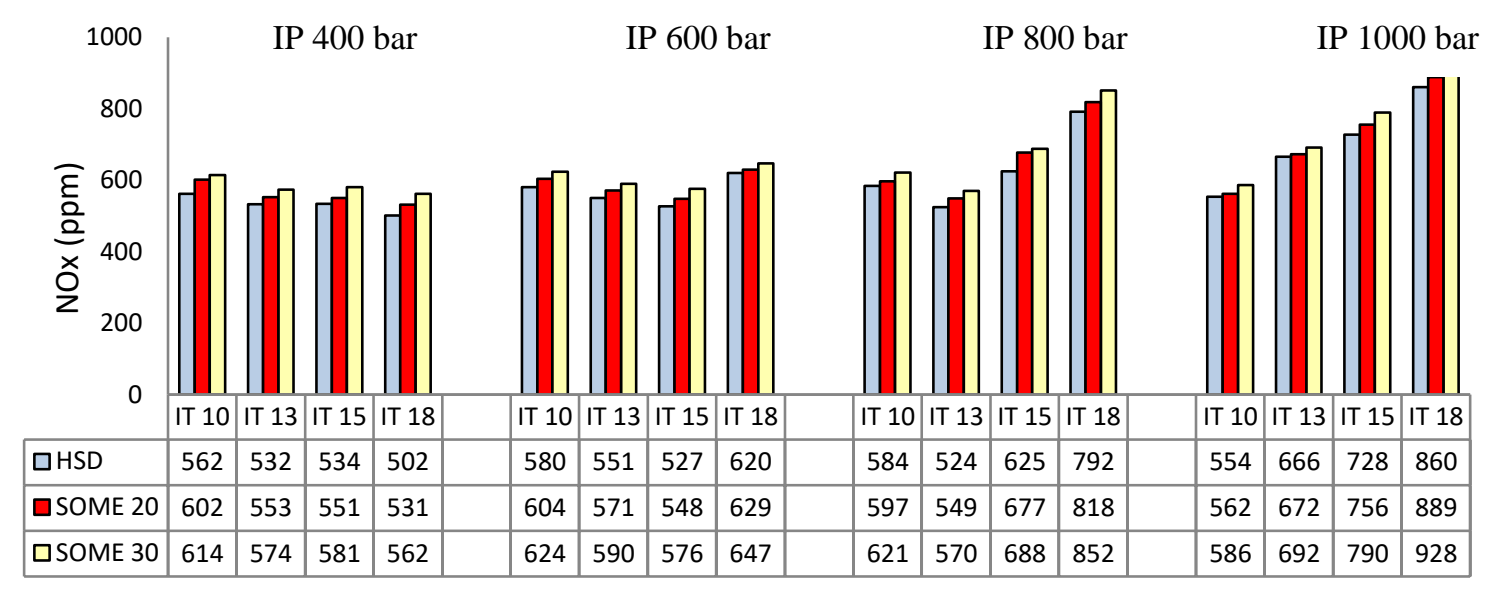

Figure 5: Influence of IP - IT on NOx for 75\% load

\section{Smoke opacity}

The variations of the Smoke opacity with IPRs and ITGs for 75\% load with SOME20, SOME30 and HSD fuel are plotted shown in Figure 6. From the figure, it is clear that as the IPR increases smoke emission decreases for the test fuel (HSD and SOME), and similar results were observed in the literature [18]. Ultra-high injection pressures lead to the reduction of soot emissions mainly attributed to better spray atomization and air entrainment [13, 23]. Increase in IPR decreases the smoke emission [18-20]. It is clear from the outcome that the smoke emission level further decreased with SOME biodiesel usage when compared to diesel fuel for each test. This is mainly due to the high oxygen content and low carbon $(\mathrm{C})$ to hydrogen $(\mathrm{H})$ ratio and the absence of aromatics in biodiesel [21]. A similar trend has been observed in the literature [29]. It is evident from Figure 6 that ITG also plays an important role in smoke opacity formation. Advancing ITG reduces the smoke formation while retarding ITG increases the same. Similar results are obtained in the literature [29].

At $75 \%$ load condition, the smoke emissions of SOME blends were less than that of diesel. The minimum smoke emission was found to be 29 HSU at IPR 1000 bar for ITG $18^{\circ}$ bTDC for SOME30. While smoke of 24 HSU was given by SOME30 for full load at 800 bar $-13^{\circ}$ ITG combination, here the combustion being helped by the closeness of the fuel bound oxygen of the biodiesel in SOME blends. Moreover, the combined effect of a proper ITG and higher IPR promote a longer duration and higher temperatures throughout the expansion stroke where oxidation of the soot particles happens [21]. 


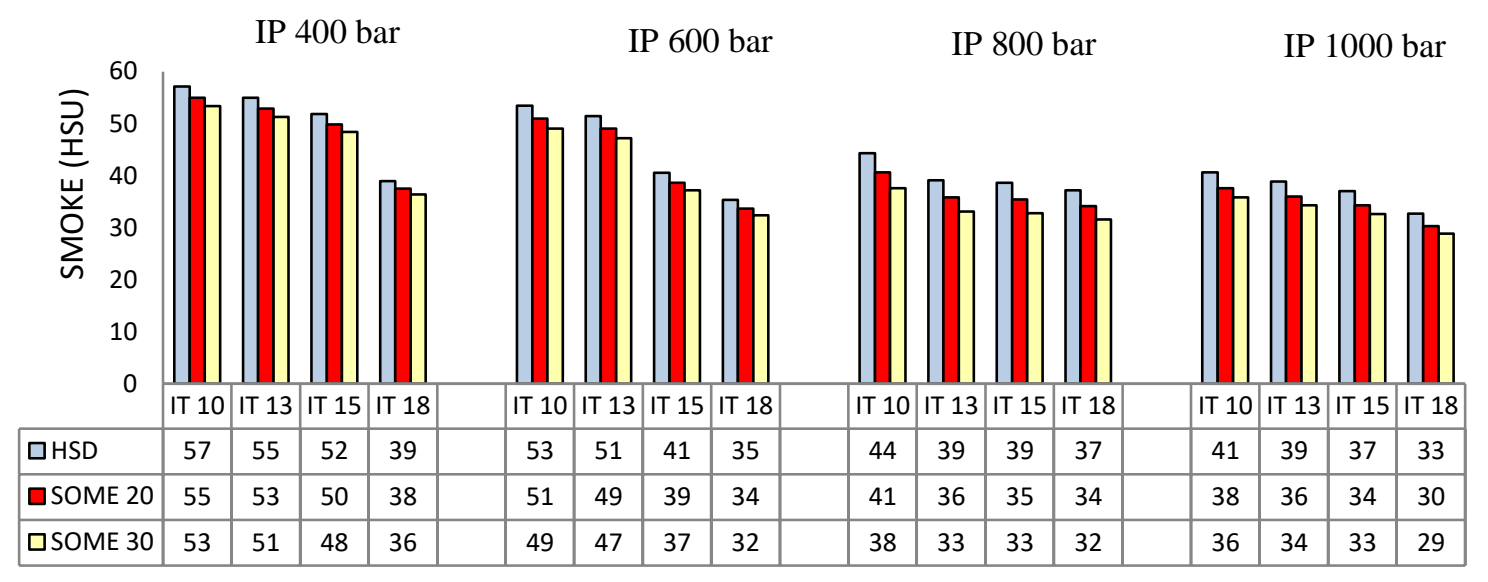

Figure 6: Influence of IP - IT on smoke opacity for $75 \%$ load.

\section{CONCLUSION}

This paper attempts to study the influence of IPR, and ITG on the performance and emission characteristics of the CRDI engine fueled with Diesel and SOME blends, and by the outcome, the following conclusions are made.

For the given engine at $75 \%$ and full load condition, the IPR of 800 bar and ITG of $13^{\circ} \mathrm{bTDC}$ combination has recorded the favourable results for all fuels tested. The highest BTE with a minimum BSFC found in IPR 800 and ITG $13^{\circ}$ bTDC combination. The NOx emission from the HSD is less than SOME blends and is found minimum at the all combinations of IPR-ITG. The smoke emissions of SOME blends are less than that of diesel for all IPRs and further decreased with increase in IPR and also with retarded ITG. A higher values of BTE obtainedwhen BSFC was low. Further, retarding ITG decreases the NOx and increases the Smoke opacity. Hence, suitable ITG should be chosen to maintain a proper trade-off between the NOx and the Smoke opacity.

To conclude this study has shown that a proper IPR and dynamic ITG would change any engine performance and emissions. From the experimental investigation, it can be concluded that the higher IPR with the perfect ITG would enhance the biodiesel blending percentage and helps to improve the performance, and also to overcome the environmental issues with depletion problem of diesel.

\section{ACKNOWLEDGEMENT}

The authors wish to acknowledge M/s Legion Brothers, Bangalore, India, for giving the chance to conduct an experimental investigation at their premises with their engine setup. The authors also like to acknowledge Bio-Park Hassan, Karnataka State Biofuel Development Board, India, for providing the Simarouba biodiesel for this study.

\section{REFERENCES}

[1] Mustafa Canakci CS, Ahmet NO, Turkcan A. Effect of injection pressure on the combustion, performance, and emission characteristics of a diesel engine fueled with methanol-blended diesel fuel. Energy \& Fuels. 2009;23:13. 
[2] Karabektas M, Ergen G, Hosoz M. Effects of the blends containing low ratios of alternative fuels on the performance and emission characteristics of a diesel engine. Fuel. 2013;112:537-41.

[3] Ye P, Boehman AL. Investigation of the impact of engine injection strategy on the biodiesel nox effect with a common-rail turbocharged direct injection diesel engine. Energy \& Fuels. 2010;24:4215-25.

[4] Shehata MS. Emissions, performance and cylinder pressure of diesel engine fuelled by biodiesel fuel. Fuel. 2013;112:513-22.

[5] Srinath Pai AS, Shiva Kumar, Shree Prakash B. A study on increased fuel injection pressure role in promoting biodiesel blends usage in a diesel engine - a review. In 3rd International Conference on Recent Trends in Engineering \& Technology, Chandwad: pp 313-317; 2014.

[6] Roy MM. Effect of fuel injection timing and injection pressure on combustion and odorous emissions in DI diesel engines. Journal of Energy Resources Technology. 2009;131:8.

[7] Emami S, Jafarmadar S. Multidimensional modeling of the effect of fuel injection pressure on temperature distribution in cylinder of a turbocharged DI diesel engine. Propulsion and Power Research. 2013;2:162-75.

[8] Pai S, Sharief A, Kumar S. Combined impact of high injection pressure and injection timing on the performance and combustion of common rail direct injection (CRDI) engine fueled with a simarouba biodiesel blend. Indian Journal of Science and Technology. 2016;9.

[9] Zhen Xu XL, Chun Guan, Zhen Huang. Effects of Injection Pressure on Diesel Engine Particle Physico-Chemical Properties. Aerosol Science and Technology. 2013;48:128-38.

[10] Monyem AJHVG, Canakci M. The effect of timing and oxidation on emissions from biodiesel-fueled engines. Transactions of the ASAE. 2000;44:8.

[11] Zhihao Ma ZH, Chongxiao Li, Xinbin Wang, Haiyan Miao. Effects of Fuel Injection Timing on Combustion and Emission Characteristics of a Diesel Engine Fueled with Diesel-Propane Blends. Energy \& Fuels. 2007;21:7.

[12] Jindal S. Combustion, performance and emissions of a DI-CI engine running on Karanj methyl ester: influence of injection timing. International Journal of Sustainable Engineering. 2011;4:136-44.

[13] Mohan B, Yang W, Chou Sk. Fuel injection strategies for performance improvement and emissions reduction in compression ignition engines-A review. Renewable and Sustainable Energy Reviews. 2013;28:664-76.

[14] Jayashankara B, Ganesan V. Effect of fuel injection timing and intake pressure on the performance of a DI diesel engine - A parametric study using CFD. Energy Conversion and Management. 2010;51:1835-48.

[15] Balusamy T, Marappan R. Effect of Injection Time and Injection Pressure on CI Engine Fuelled with Methyl Ester of Thevetia Peruviana Seed Oil. International Journal of Green Energy. 2010;7:397-409.

[16] Raeie N, Emami S, Karimi Sadaghiyani O. Effects of injection timing, before and after top dead center on the propulsion and power in a diesel engine. Propulsion and Power Research. 2014;3:59-67.

[17] Venkatraman. MDG. Effect of Compression ratio, Injection Timing and Injection Pressure on a DI Diesel engine for better performance and emission fueled with diesel diesel biodiesel blends. International Journal of Applied Engineering Research. 2010;1:11. 
[18] Gumus M, Sayin C, Canakci M. The impact of fuel injection pressure on the exhaust emissions of a direct injection diesel engine fueled with biodiesel-diesel fuel blends. Fuel. 2012;95:486-94.

[19] Kannan GR, Anand R. Experimental evaluation of DI diesel engine operating with diestrol at varying injection pressure and injection timing. Fuel Processing Technology. 2011;92:2252-63.

[20] Sayin C, Gumus M, Canakci M. Effect of fuel injection pressure on the injection, combustion and performance characteristics of a DI diesel engine fueled with canola oil methyl esters-diesel fuel blends. Biomass and Bioenergy. 2012;46:43546.

[21] Kannan GR, Anand R. Effect of injection pressure and injection timing on DI diesel engine fuelled with biodiesel from waste cooking oil. Biomass and Bioenergy. 2012;46:343-52.

[22] Belagur VK, Chitimini VR. Influence of static injection timing on combustion, emission and performance characteristics of DI diesel engine fuelled with honne oil methyl ester. International Journal of Ambient Energy. 2012;33:65-74.

[23] Jaichandar S, Annamalai K. Combined impact of injection pressure and combustion chamber geometry on the performance of a biodiesel fueled diesel engine. Energy. 2013;55:330-9.

[24] Agarwal AK, Atul Dhar, Jai GopalGupta, Woong Il Kim, Kibong Choi, Chang Sik Lee, Sungwook Park. Effect of fuel injection pressure and injection timing of karanja biodiesel blends on fuel spray, engine performance, emissions and combustion characteristics. Energy Conversion and Management. 2015;91:30214.

[25] DeepeshSonar SLS, DilipSharma, Anmesh Srivastava \& Rahul Goyal,. Performance and emission characteristics of a diesel engine with varying injection pressure and fuelled with raw mahua oil (preheated and blends) and mahua oil methyl ester. Clean Technologies and Environmental Policy. 2014;17:1499-511.

[26] Atul Dhar AKA. Experimental investigations of the effect of pilot injection on performance, emissions and combustion characteristics of Karanja biodiesel fuelled CRDI engine. Energy Conversion and Management. 2015;93:10.

[27] Senthil R, Silambarasan R, Pranesh G. The influence of injection timing on the performance and emission characteristics of an Annona methyl ester operated diesel engine. Biofuels. 2016;7:437-45.

[28] Shahir CPJ, Suresh, Vinod V. Experimental Investigation on Performance and Emission Characteristics of a Common Rail Direct InjectionEngine Using Animal Fat Biodiesel Blends. International Conference on Power Engineering, Computing and Control. VIT University. Chennai Campus: Energy Procedia; 2017.

[29] Sam Yoon MK, Han Kim, Nag Choi Effects of Canola Oil Biodiesel Fuel Blends on Combustion, Performance, and Emissions Reduction in a Common Rail Diesel Engine. Energies. 2014;7:8132-49.

[30] Avinash KA, Atul D. Combustion, performance and emissions characteristics of a newly developed CRDI single cylinder diesel engine. Sadhana Indian Academy of Sciences; 2015. p. 18.

[31] Lin G-H, Kuo C-P. Effects of the injection timing on the engine performance and the exhaust emissions of a diesel engine fuelled by tyre pyrolysis oil-diesel blends. Proceedings of the Institution of Mechanical Engineers, Part D: Journal of Automobile Engineering. 2013;227:1153-61. 
[32] Belachew Tesfa FG, Rakesh Mishra and Andrew Ball. Emission Characteristics of a CI Engine Running with a Range of Biodiesel Feedstocks energies. 2014;7:17.

[33] Keshav S. Varde TW. Characteristics of High Pressure Spray and Exhaust Emissions in a Single Cylinder DI Diesel Engine. FISITA World Automotive Congress. 2000:7. 